\title{
Within- and Between-Population Polymorphism of the mtDNA Control Region of the Speckled Ground Squirrel (Spermophilus suslicus)
}

\author{
V. A. Matrosova, L. E. Savinetskaya, O. N. Shekarova, S. V. Pivanova, M. Yu. Rusin, \\ I. A. Volodin, E. V. Volodina, and A. V. Tchabovsky \\ Presented by Academician D.S. Pavlov November 28, 2013
}

Received November 28, 2013

DOI: $10.1134 / \mathrm{S} 0012496614020197$

Fragmentation of distribution ranges and their reduction frequently influence the genetic structure of wild animal populations interfering with gene exchange between different parts of the distribution area, decreasing effective population size, and elevating the level of inbreeding [1]. In small isolated populations, gene drift can decrease genetic diversity, thereby limiting the adaptation to environmental changes and increasing the risk for elimination of local populations [2-4].

Ground squirrels are a convenient model for studying how the fragmentation of distribution range influences the genetic structure of populations. It has been shown for different species and regions that transformation of habitats and their fragmentation caused by human activities limit the gene flow between isolated populations and reduce genetic diversity within populations, which elevates the risk of their elimination and demands special efforts for their preservation $[2,3,5]$. Reintroduction and exchange of individuals between isolated populations may help to maintain the genetic diversity of populations and their stability; however, this requires knowledge of their genetic structure, origin, and the degree of within- and between-population polymorphisms $[2,3,5]$.

The speckled ground squirrel (Spermophilus suslicus) is a vulnerable species living in the steppe and for-

Engelhardt Institute of Molecular Biology, Russian Academy of Sciences, Moscow, Russia Severtsov Institute of Ecology and Evolution, Russian Academy of Sciences, Moscow, Russia Lipetsk State Pedagogical University, Lipetsk, Russia Schmalhausen Institute of Zoology, National Academy of Sciences of Ukraine, Kiev, Ukraine

Moscow State University, Moscow, 119992 Russia

Moscow Zoo, Moscow, Russia

e-mail:v.matrosova@gmail.com est-steppe zones of Russia, Ukraine, Moldova, and partially in Poland and Belarus. The ground squirrels from the northeastern part of the distribution range have a diploid chromosome set with $2 n=34$ and $\mathrm{NF}=68$ versus $2 n=36$ and NF $=72$ in the southwestern part [6]. Although several researchers regard the 36-chromosome form as a separate species [7], we adhere in this study to the traditional systematics $[8,9]$. In the past decades, the ground squirrel colonies have reduced in size, and the species has disappeared in some localities; only highly isolated small colonies are preserved [10]. This species is included into the list of endangered species in the Moscow, Nizhni Novgorod, Bryansk, Penza, and some other regions and the Republic of Tatarstan in Russia, as well as in Moldova. In Ukraine, both forms of the speckled ground squirrel were added to the third edition of endangered species list (2009), the 34-chromosome form being regarded as a Endangered species and the 36-chromosome form, as Not Evaluated. In Belarus and Poland, this species has also been protected since 2006 and 1984, respectively. In 1996-2008, this species had the status of a Vulnerable species in the IUCN Red List; however, its status was later unjustifiably decreased to Near Threatened.

Our earlier bioacoustic analysis of the populations living in Moscow and Lipetsk regions revealed significant between-population differences in the alarm calls, which suggested the presence of considerable genetic differences between these populations [11]. This assumption has been confirmed by the data on polymorphism in the left domain of mtDNA control region $(310 \mathrm{bp})$ of the speckled ground squirrel, namely, a considerable level of differences between 20 populations living in different parts of the species distribution range [12]. It has been found that the phylogeographic structure in the western part of the distribution range is more pronounced as compared with 
Table 1. Characteristics of speckled ground squirrel populations $(N$, the number of assayed animals in population; $N_{\text {hapl }}$, number of found haplotypes; $N_{\text {uniq }}$, number of unique haplotypes; $\pi$, nucleotide diversity; and S.E., standard error)

\begin{tabular}{l|c|c|c|c|c}
\hline \multicolumn{1}{c|}{ Population } & $N$ & $N_{\text {hapl }}$ & $N_{\text {uniq }}$ & $\pi$ & $(S . E)$. \\
\hline Zaraisk & 10 & 1 & 0 & 0.000 & $(0.000)$ \\
Lipetsk & 10 & 1 & 0 & 0.000 & $(0.000)$ \\
Michurinsk & 10 & 3 & 2 & 0.001 & $(0.000)$ \\
Novosel'skoe & 10 & 5 & 2 & 0.005 & $(0.001)$ \\
Ozernoe & 10 & 4 & 2 & 0.009 & $(0.002)$ \\
\hline
\end{tabular}

the eastern part. All the examined individuals had unique haplotypes; however, only a single individual from each colony (except for four colonies, where two-three individuals were assayed) was analyzed, preventing estimation of within-population variation and its comparison with between-population polymorphism. In addition, only a fragment of the mtDNA control region was analyzed.

The goal of this study was to assess the within- and between-population polymorphisms of the complete mtDNA control region for five speckled ground squirrel populations of Central Russia and Ukraine.

\section{MATERIALS AND METHODS}

Sampling was performed in the April-August of 2005-2013 during aboveground activity of ground squirrels. The objects were 50 individually marked adult speckled ground squirrels, ten individuals from five isolated wild populations. The individuals were selected from the amount of available data so that the chance of including close relatives would be minimal.

(1) Zaraisk (544 $47^{\prime} 68^{\prime \prime} \mathrm{N}, 38^{\circ} 42^{\prime} 23^{\prime \prime}$ E) population: a community on an open dry meadow with a high grass stand near the village Velikoe pole, Zaraisk district, Moscow region.

(2) Lipetsk (52 $36^{\prime} 28^{\prime \prime} \mathrm{N}, 39^{\circ} 26^{\prime} 38^{\prime \prime}$ E) population: a community on a municipal cemetery near the village Kosyrevka. The cemetery occupies former farmlands (since 1980), currently being a complex anthropogenic landscape with prevalence of introduced plant species.

(3) Michurinsk (52 $\left.51^{\prime} 44^{\prime \prime} \mathrm{N}, 40^{\circ} 47^{\prime} 01^{\prime \prime} \mathrm{E}\right)$ population: this is the last preserved fragment of an earlier successful colony in the periphery of the village Dmitrievka, Michurinsk district, Tambov region, adjacent to federal highway M-6.

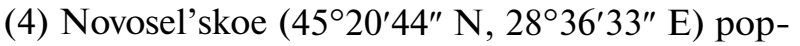
ulation: a community near the village Novosel'skoe, Reni district, Odessa region, on a low bank of Lake Yalpug with prevalence of overgrazed pasture-ruderal plants at a moderate grazing pressure.
(5) Ozernoe $\left(45^{\circ} 25^{\prime} 92^{\prime \prime} \mathrm{N}, 28^{\circ} 40^{\prime} 04^{\prime \prime}\right.$ E) population: a colony near the village Ozernoe, Reni district, Odessa region, on a high dry bank of the Yalpug Lake with overgrazed grass stand. The two last colonies were located at a distance of $12 \mathrm{~km}$ from one another and separated by two large meridionally stretched lakes, which may be regarded as a geographic barrier for ground squirrels.

The first three populations belong to the eastern part of the speckled ground squirrel distribution range and the last two, to its western part.

Animals were captured with live traps, labeled with permanent marks, assayed for sex and age, and released. The trapping point was determined with a GPS navigator. The geographic distances between populations were calculated as linear distances $(\mathrm{km})$ based on GPS coordinates using MapSource.

DNA was isolated from soft tissue specimens (finger pad sections) fixed with $96 \%$ ethanol by phenolchloroform extraction or a Kingfisher ${ }^{\circledR}$ Flex (Thermo Scientific, USA) robot for DNA extraction and Magna DNA Prep (Izogen, Russia) kit according to the manufacturers' protocols.

The complete control region flanked by a fragment of the tRNA-Pro gene and the tRNA-Phe gene (total length, $1148 \mathrm{bp}$ ) was amplified using the primers MDL1 and H00651 [13]. Polymerase chain reaction (PCR) was conducted in a volume of $25 \mathrm{~mL}$ using the reagents from Dialat (Russia); the reaction mixture contained $5 \mathrm{pM}$ of each primer, $0.1-0.2 \mu \mathrm{g}$ of DNA, and $\mathrm{ddH}_{2} \mathrm{O}$ to the final volume. The PCR comprised 30 cycles of $1 \mathrm{~min}$ at $94^{\circ} \mathrm{C}, 1 \mathrm{~min}$ at $62^{\circ} \mathrm{C}$, and $3 \mathrm{~min}$ at $72^{\circ} \mathrm{C}$. The PCR products were separated in $1.5 \%$ agarose gel stained with ethidium bromide, visualized in UV light, cut off, and purified using a MinElute Gel Extraction kit (Qiagen, Germany). Sequencing was performed in an ABI 3730 automated genetic analyzer using a BidDye Terminator v3.1 Cycle Sequencing Kit (Applied Biosystems, USA) and each of the pair of internal primers (designed by V.L. Surin), namely, MDL2D (5'-CCAAATGACTATCCCCTACC-3') and MDL3R (5'-GACTAATAAGTCCAGCTACA-3').

The resulting nucleotide sequences were aligned with the help of SeqMan (Lasergene, USA) and BioEdit [14], as well as manually. The MEGA 5 software [15] was used for statistical data processing and construction of phylogenetic tree. The percentage of between-population differences was determined according to the number of nucleotide substitutions in the aligned sequences. The within- and between-group genetic differences $\left(\mathrm{K}_{2} \mathrm{P}\right.$ distances $)$ were estimated according to the Kimura two-parameter model. The phylogenetic tree was constructed using unweighted pair group method average (UPGMA). Node support values in phylogenetic tree was estimated according to bootstrap support (1000 replicates). The nucleotide sequence of 


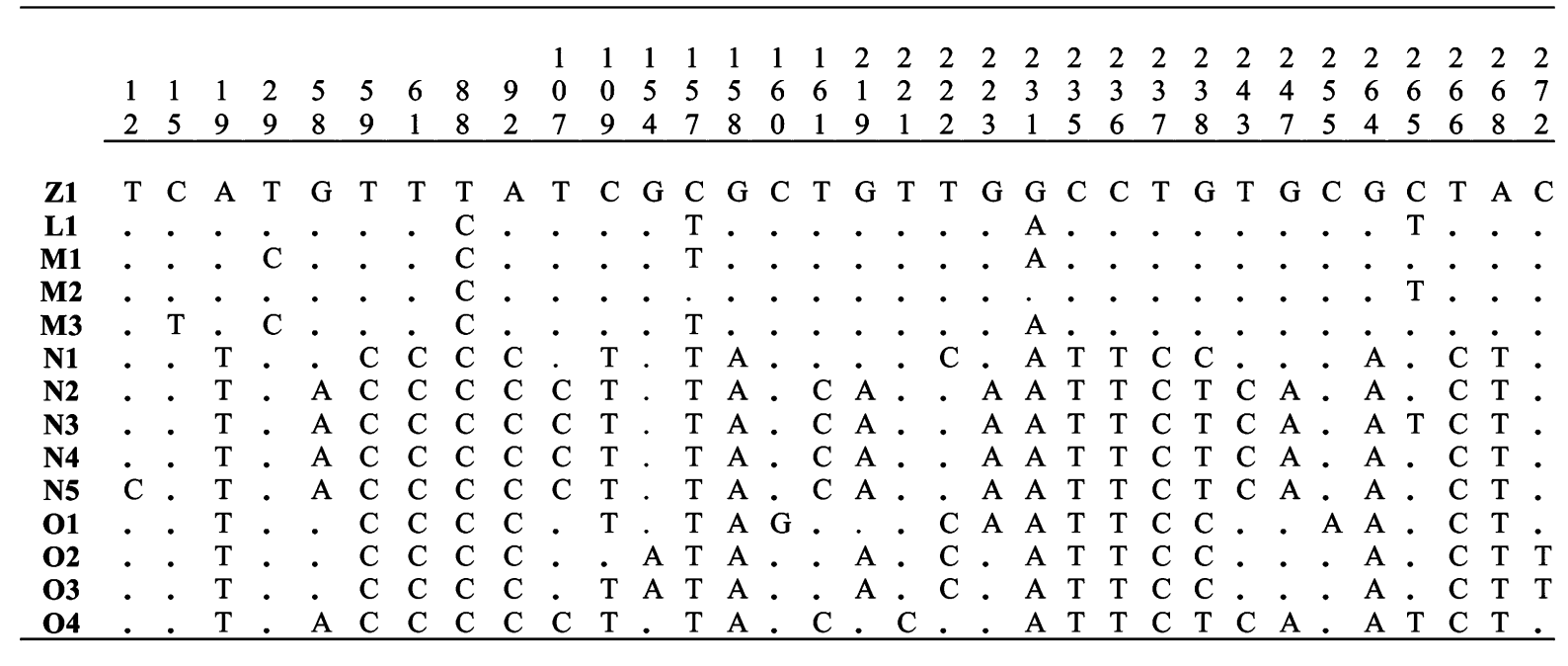

\begin{tabular}{lllllllllllllllllllllllllllllllll}
2 & 2 & 2 & 3 & 3 & 4 & 4 & 5 & 5 & 6 & 6 & 7 & 7 & 7 & 7 & 8 & 8 & 8 & 8 & 8 & 8 & 8 & 8 & 8 & 8 & 9 & 9 & 9 & 9 & 9 & 9 & 9 & 9 \\
7 & 7 & 9 & 3 & 6 & 1 & 6 & 0 & 0 & 2 & 8 & 0 & 1 & 7 & 8 & 1 & 2 & 2 & 4 & 4 & 5 & 7 & 8 & 9 & 9 & 0 & 0 & 1 & 2 & 7 & 8 & 9 & 9 \\
5 & 6 & 0 & 7 & 1 & 1 & 0 & 1 & 2 & 6 & 9 & 3 & 2 & 5 & 4 & 6 & 3 & 4 & 0 & 8 & 4 & 5 & 1 & 5 & 6 & 0 & 8 & 1 & 2 & 0 & 6 & 8 & 9 \\
\hline
\end{tabular}

\begin{tabular}{|c|c|c|c|c|c|c|c|c|c|c|c|c|c|c|c|c|c|c|c|c|c|c|c|c|}
\hline & T & C $\mathrm{C}$ & $\mathrm{C} \quad \mathrm{G}$ & $\mathrm{C}$ & A & A & $\mathrm{A} \quad \mathrm{T}$ & A & A & $c$ & C A & $A C$ & $\mathrm{~T} \quad \mathrm{~T}$ & T C & 1 & $A C$ & $\vec{v}$ & - & A & 1 & $1 \quad 1$ & & $c$ & - \\
\hline & & & A & & . & . & . & . & . & . & & & & & & & & - & & & & & & \\
\hline M1 & & & A & & . & . & & • & & . & & & & & & & & - & & & & & & \\
\hline & . & & A & - & . & . & - & • & . & . & & & & & & & & - & & & & & & \\
\hline & & & $A$ & & & & & & & & & & & & & & & & & & & & & \\
\hline 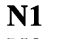 & & & $\mathrm{T}$ & $\mathrm{T}$ & $\mathrm{T}$ & G & $\begin{array}{ll}G \quad C \\
\text {. }\end{array}$ & & G C & 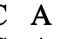 & $\mathrm{T} \quad \mathrm{C}$ & $\begin{array}{ll}C & T\end{array}$ & & A & C 7 & $\mathrm{~T}$ & & A & $\mathrm{T}$ & & & & & \\
\hline N2 & A & & $\mathrm{T}$ & $\mathrm{T}$ & ( & G & G & & G C & $\mathrm{A}$ & $\mathrm{T} C \mathrm{C}$ & $\mathrm{C} \quad \mathrm{T}$ & & . & $\mathrm{C}$ & $\mathrm{T}$ & & A & $\mathrm{T}$ & C & & & 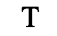 & \\
\hline$\sqrt{13}$ & A & & $\mathrm{T}$ & $\mathrm{T}$ & C & G & G & . & G C & $\mathrm{A}$ & $\mathrm{T} C \mathrm{C}$ & C & & . & $\mathrm{C}$ & & & A & $\mathrm{T}$ & & & E & 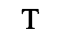 & \\
\hline N4 & & & $\mathrm{T}$ & $\mathrm{T}$ & C & G & G & • & & 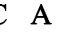 & $\mathrm{T} C \mathrm{C}$ & $\begin{array}{ll}\mathrm{C} \\
\mathrm{C}\end{array}$ & & - & & $\mathrm{T}$ & A & A & $\mathrm{T}$ & & & & $\mathrm{T}$ & \\
\hline vo & A & & $\mathrm{T}$ & & C & G & G & & G C & & & & & & & $\mathrm{T}$ & & & $\mathrm{T}$ & & & & & \\
\hline 01 & & & $\mathrm{~T}$ & $\mathrm{~T}$ & $\mathrm{~T}$ & G & G & & & & $\begin{array}{ll}\mathrm{T} & \mathrm{C}\end{array}$ & C & & 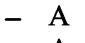 & & & & A & $\mathrm{T}$ & & & & & \\
\hline 02 & A & & $\mathrm{T}$ & & & & G & & G C & & & C & & & & & & & & & & & & \\
\hline $\mathbf{0 3}$ & A & & T & $\mathrm{T}$ & $\mathrm{T}$ & & G & & G & & $\mathrm{T}$ & & & - & & $\mathrm{T}$ & & & $\mathrm{T}$ & & & & & \\
\hline 04 & A & & & & $\mathrm{T}$ & & G & & & & & & & & & & & & & & & & & \\
\hline
\end{tabular}

Fig. 1. Variation in the nucleotide sequence of mtDNA control region (999-1001 bp) of the speckled ground squirrel. Only variable positions are shown; numbering corresponds to the complete structures aligned relative to haplotype Z1; dots denote identical nucleotides and dashes, deletions.

homologous mtDNA fragment of the Perote ground squirrel (Xerospermophilus perotensis) (NCBI acc. no. JQ326958.1 [5]) was used as an outgroup.

\section{RESULTS AND DISCUSSION}

We have determined the nucleotide sequence of the complete mtDNA control region (999-1001 bp) in 50 speckled ground squirrel individuals belonging to five populations (Table 1, Fig. 1). Totally, 61 sites (6\% of the total fragment length) have proved to be variable and 56 of them, phylogenetically significant. Nucleotide diversity $(\pi)$ varied from zero to 0.009 in different populations, amounting to $0.024(S . E .=0.003)$ in the pooled sample set (Table 1 ). The mean nucleotide contents were $31 \%$ for A, $34 \%$ for $\mathrm{T}, 12 \%$ for $\mathrm{G}$, and $23 \%$ for $\mathrm{C}$. The ratio of transitions to transversions was $3: 1$; 14 haplotypes were identified among the exam- ined individuals (Table 2, Fig. 1). The same haplotype was never met beyond the population where it was observed.

The complete sample set of ground squirrels fell into two large groups, comprising three eastern (Zaraisk, Lipetsk, and Michurinsk) and two western (Novosel'skoe and Ozernoe) populations, respectively (Fig. 2). The eastern populations were weakly structured: the genetic distances between individuals within the Zaraisk and Lipetsk populations were zero, while only single nucleotide substitutions were observed in the Michurinsk population (Table 1, Fig. 2). The within-population variation of the western Novosel'skoe and Ozernoe populations was considerably higher compared with the eastern ones; different phyletic lineages were present there. The betweenpopulation distances were larger than the within-population ones, including the distances for the adjacent 
Table 2. Examined speckled ground squirrel individuals and the found haplotypes of mtDNA control region (Z, Zaraisk population; L, Lipetsk; M, Michurinsk; N, Novosel'skoe; O, Ozernoe; m, male; and f, female; unique haplotypes are boldfaced)

\begin{tabular}{|c|c|c|c|c|c|c|c|}
\hline Specimen & Sex & Haplotype & NCBI acc. no. & Specimen & Sex & Haplotype & NCBI acc. no. \\
\hline Z147 & $\mathrm{m}$ & $\mathrm{Z1}$ & KF934335 & M18 & $\mathrm{m}$ & M1 & KF934360 \\
\hline Z153 & $\mathrm{m}$ & $\mathrm{Z} 1$ & KF934336 & M19 & $\mathrm{m}$ & M1 & KF934361 \\
\hline Z381 & $\mathrm{m}$ & $\mathrm{Z} 1$ & KF934337 & M21 & $\mathrm{m}$ & M1 & KF934362 \\
\hline Z412 & $\mathrm{f}$ & $\mathrm{Z} 1$ & KF934338 & M22 & $\mathrm{f}$ & M1 & KF934363 \\
\hline Z4057 & $\mathrm{f}$ & $\mathrm{Z} 1$ & KF934339 & M23 & $\mathrm{f}$ & M1 & KF934364 \\
\hline Z4064 & $\mathrm{m}$ & $\mathrm{Z} 1$ & KF934340 & N14 & $\mathrm{m}$ & N1 & KF934365 \\
\hline Z4066 & $\mathrm{m}$ & $\mathrm{Z} 1$ & KF934341 & N16 & $\mathrm{f}$ & $\mathrm{N} 2$ & KF934366 \\
\hline Z4070 & $\mathrm{f}$ & $\mathrm{Z} 1$ & KF934342 & $\mathrm{N} 27$ & $\mathrm{f}$ & N1 & KF934367 \\
\hline Z4143 & $\mathrm{m}$ & $\mathrm{Z} 1$ & KF934343 & $\mathrm{N} 48$ & $\mathrm{f}$ & N3 & KF934368 \\
\hline Z4144 & $\mathrm{f}$ & $\mathrm{Z} 1$ & KF934344 & N52 & $\mathrm{m}$ & N3 & KF934369 \\
\hline L34 & $\mathrm{f}$ & L1 & KF934345 & N56 & $\mathrm{m}$ & $\mathrm{N} 2$ & KF934370 \\
\hline L35 & $\mathrm{f}$ & L1 & KF934346 & N211 & $\mathrm{f}$ & $\mathrm{N} 2$ & KF934371 \\
\hline L36 & $\mathrm{m}$ & L1 & KF934347 & $\mathrm{N} 213$ & $\mathrm{~m}$ & N3 & KF934372 \\
\hline L37 & $\mathrm{m}$ & L1 & KF934348 & $\mathrm{N} 222$ & $\mathrm{~m}$ & N4 & KF934373 \\
\hline L38 & $\mathrm{m}$ & L1 & KF934349 & $\mathrm{N} 226$ & $\mathrm{~m}$ & N5 & KF934374 \\
\hline L39 & $\mathrm{f}$ & L1 & KF934350 & O101 & $\mathrm{f}$ & 01 & KF934375 \\
\hline L46 & $\mathrm{m}$ & L1 & KF934351 & O103 & $\mathrm{f}$ & $\mathrm{O} 2$ & KF934376 \\
\hline L47 & $\mathrm{m}$ & L1 & KF934352 & O105 & $\mathrm{m}$ & $\mathbf{O 3}$ & KF934377 \\
\hline L48 & $\mathrm{f}$ & L1 & KF934353 & O108 & $\mathrm{m}$ & $\mathrm{O} 4$ & KF934378 \\
\hline L49 & $\mathrm{m}$ & L1 & KF934354 & O109 & $\mathrm{f}$ & $\mathrm{O} 4$ & KF934379 \\
\hline M11 & $\mathrm{m}$ & M1 & KF934355 & O111 & f & $\mathrm{O} 4$ & KF934380 \\
\hline M13 & $\mathrm{f}$ & M1 & KF934356 & $\mathrm{O} 112$ & $\mathrm{f}$ & $\mathrm{O} 4$ & KF934381 \\
\hline M15 & $\mathrm{m}$ & M2 & KF934357 & O113 & $\mathrm{f}$ & $\mathrm{O} 2$ & KF934382 \\
\hline M16 & $\mathrm{f}$ & M3 & KF934358 & O114 & $\mathrm{f}$ & $\mathrm{O} 4$ & KF934383 \\
\hline M17 & $\mathrm{f}$ & M1 & KF934359 & O201 & $\mathrm{m}$ & $\mathrm{O} 4$ & KF934384 \\
\hline
\end{tabular}

Table 3. Matrix of the genetic and geographic distances between the examined speckled ground squirrel populations

\begin{tabular}{l|c|c|c|c|c}
\hline \multicolumn{1}{c|}{ Population } & Zaraisk & Lipetsk & Michurinsk & Novosel'skoe & Ozernoe \\
\hline Zaraisk & & 0.005 & 0.005 & 0.049 & 0.048 \\
Lipetsk & 249 & & 0.002 & 0.045 & 0.043 \\
Michurinsk & 255 & 95 & & 0.046 & 0.045 \\
Novosel'skoe & 1274 & 1130 & 1217 & & 0.010 \\
Ozernoe & 1262 & 1119 & 1206 & 12 & \\
\hline
\end{tabular}

Nucleotide distances between populations ( $\mathrm{K}_{2} \mathrm{P}$ distance) are shown above diagonal and geographic distances between populations $(\mathrm{km})$ are shown below.

highly variable Novosel'skoe and Ozernoe populations (Tables 2 and 3). The genetic distance between all eastern and all western populations was $4.4 \%$.

The genetic distances between geographically remote populations have proved to be considerably larger compared with the isolated populations of the same or adjacent regions (Table 3 ). The nucleotide differences accumulate gradually with an increase in the distance between populations due to gene drift. This effect is enhanced by fragmentation of the distribution range and the presence of ecological or geographical barriers, as suggested by considerable between-population differences of adjacent but isolated populations.

Analysis of the variation in the complete mtDNA control region suggests that the ground squirrels from the east of the distribution range display considerably 


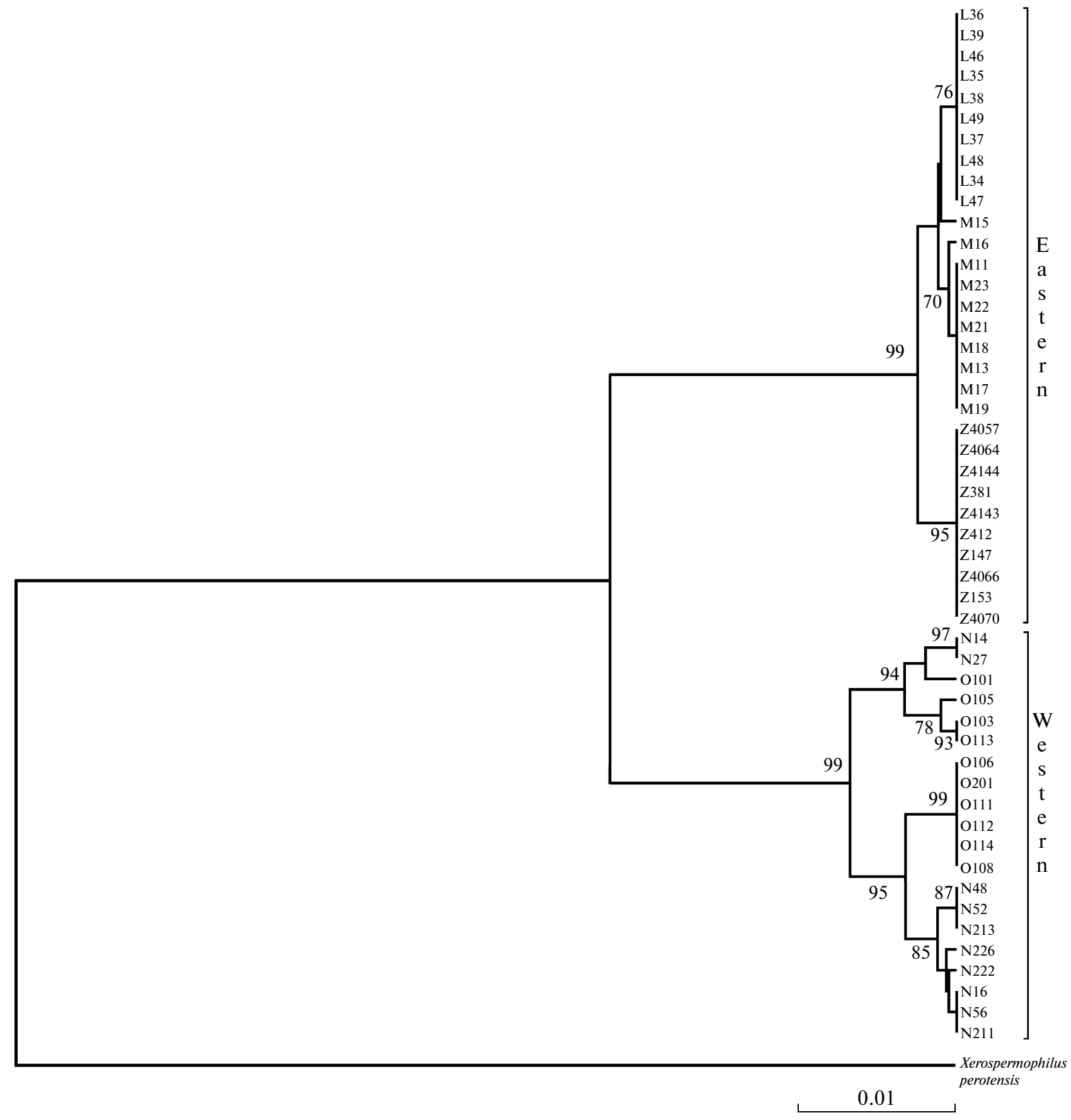

Fig. 2. Phylogenetic tree (UPGMA) for the haplotypes of mtDNA control region of the speckled ground squirrel. Bootstrap support for 1000 replicates is shown near branches only for the values exceeding 70\%; sample numbers correspond to those listed in Table 2.

lower genetic diversity as compared with the western populations of this species. Thus, our data agree with a recent estimation of the polymorphism in the left domain of speckled ground squirrel mtDNA control region from different parts of the distribution range [12].

The pooled genetic diversity of the eastern populations studied suggests that they are less successful as compared with the western populations. The former are considerably fragmented and intensely stressed by anthropogenic factors. The examined western populations from Ukrainian Bessarabia are more successful, on the one hand, in genetic diversity and, on the other, in the population size and area of colonies.

Molecular genetic methods are widely used for solving various problems in nature conservation, including the search for the populations suitable for 
animal reintroduction. A donor population should be maximally close genetically to the restored one.

It is evident that only integrated analysis of both genomic (nuclear and mitochondrial DNAs) and phenotypic (including acoustic) markers can provide more comprehensive information. It is necessary to increase the number of examined populations and to use more variable genomic markers, such as microsatellites from the nuclear DNA.

\section{ACKNOWLEDGMENTS}

We are grateful to staff of the DNA sequencing centre "Genome" at the Institute of Molecular Biology, Russian Academy of Sciences, P.A. Sorokin and E.N. Solovjeva for their assistance in DNA isolation; to the researchers of the Laboratory of Medical Epizootology of the Mechnikov Ukrainian National Antiplague Institute (Odessa, Ukraine), as well as to A. Rashevskaya and Yu. Milobog, for their assistance in sampling; to V.S. Lebedev, A.A. Bannikova, O.A. Ermakov, S.V. Titov, N.A. Poyarkov, E.N. Solovjeva, V.S. Artamonova, and I.V. Pal'ko for methodical advice; and to M.V. Kholodova for review of the manuscript and valuable criticism.

This study was supported by the Russian Foundation for Basic Research (project nos. 12-04-00260 and 12-04-31274) and the Presidium of the Russian Academy of Sciences under the Subprogram "Dynamics and Preservation of Gene Pools" of the Basic Research Program "Living Nature: Current State and Problems in Development."

\section{REFERENCES}

1. Garner, A., Rachlow, J.L., and Hicks, J.F., Conservation Biol., 2005, vol. 19, no. 4, pp. 1215-1221.

2. Frankham, R., C.R. Biol., 2003, vol. 326, pp. 22-29.

3. Ricanova, S., Bryja, J., Cosson, J.F., et al., Conservation Genet., 2011, vol. 12, pp. 1115-1129.

4. Titov, S.V., Savinetskaya, L.E., and Tchabovsky, A.V., Dokl. Biol. Sci., 2009, vol. 429, no. 1, pp. 523-525.

5. Ochoa, A., Gasca, J., Ceballos, G.J., et al., J. Mammal., 2012, vol. 93, no. 4, pp. 1061-1074.

6. Vorontsov, N.N. and Lyapunova, E.A., Byull. Mosk. $O$ va Ispyt. Prir. Otd. Biol., 1970, vol. 75, no. 3, pp. 112126.

7. Zagorodnyuk, M.V. and Fedorchenko, A.A., Vestn. Zool., 1995, nos. 5-6, pp. 49-58.

8. Ognev, S.I., Zveri SSSR i prilezhashchikh stran (Wild Mammals of the Soviet Union and Neighboring Countries), Moscow: Akad. Nauk SSSR, 1947, vol. 5.

9. Mammal Species of the world. A taxonomic and Geographic Reference, Wilson, D.E. and Reeder, D.M., Eds., Baltimore: John Hopkins Univ. Press, 2005, 3rd ed.

10. Shekarova, O.N., Byull. Mosk. O-va Ispyt. Prir. Otd. Biol., 2006, vol. 111, no. 5, pp. 90-95.

11. Matrosova, V.A., Pivanova, S.V., Savinetskaya, L.E., et al., Zool. Zh., 2012, vol. 91, no. 4, pp. 453-463.

12. Ermakov, O.A., Surin, V.L., and Titov, S.V., Izv. Peterb. Gos. Ped. Univ. im. V.G. Belinskogo, 2011, vol. 25, pp. 176-180.

13. Ermakov, O.A., Surin, V.L., Titov, S.V., et al., Genetika, 2002, vol. 38, no. 7, pp. 950-964.

14. Hall, T.A., Nucleic Acids Symp. Ser., 1999, vol. 41, pp. 95-98.

15. Tamura, K., Peterson, D., Peterson, N., et al., Mol. Biol. Evol., 2011, vol. 28, pp. 2731-2739.

Translated by G. Chirikova 